\title{
Normative data for the 6-min walk test in 11-14 year-olds: a population-based study
}

Mario Kasović 1,2 , Lovro Štefan ${ }^{1,2,4^{*}}$ and Vilko Petrić ${ }^{3}$

\begin{abstract}
Background: The 6-min walk test (6MWT) has become an established measure for assessing exercise capacity in children with chronic diseases. However, little evidence has been provided regarding population-based normal data in healthy children. The main purpose of the study was to provide normative data in a large sample of children.

Methods: In this cross-sectional study, 4352 children between 11 and 14 years were recruited (66\% girls). The main outcome measure was the distance walked for six minutes. Sex- and age-specific percentile values (5th, 15th, 25th, 50th, 75th, 85th and 95th) for the 6MWT were created and the differences and correlations were examined by the analysis of variance and Pearson's coefficient of correlation.
\end{abstract}

Results: The mean distance walked in 6 min was $576 \pm 93 \mathrm{~m}$ in boys and $545 \pm 92 \mathrm{~m}$ in girls, respectively. The mean walking speed for boys and girls was $98 \pm 5 \mathrm{~m} / \mathrm{min}$ and $91 \pm 6 \mathrm{~m} / \mathrm{min}$. Older boys and girls performed better, compared to their younger counterparts ( $p$ for age $<0.001)$. The 6MWT was significantly correlated with age $(r=0.24$, $p<0.001)$, height $(r=0.09, p<0.001)$, weight $(r=-0.13, p<0.001)$ and body-mass index $(r=-0.26, p<0.001)$.

Conclusions: This is the first population-based study aiming to provide normative data for the 6MWT in healthy children between 11 to 14 years. Children in lower percentiles are 'target groups'for special intervention aiming to enhance the performance.

Keywords: Pediatric, Exercise capacity, Standards, Testing

\section{Background}

The six-minute walk test (6MWT) has become a widely used measure for assessing functional exercise capacity at submaximal level $[1,2]$. It is described as the distance person can walk at self-paced speed over the period of 6 min [3-5]. Previous evidence highlights the importance of using the 6MWT, in terms of its safety, reliability and validity properties, and usefulness in assessing functional assessment and is a powerful prognostic marker for functional capacity in both healthy and unhealthy individuals [6]. Factors associated with shorter and longer 6-min distance have been described previously [6]. The 6MWT

\footnotetext{
*Correspondence: lovro.stefan1510@gmail.com

1 Department of General and Applied Kinesiology, Faculty of Kinesiology,

University of Zagreb, Horvaćanski zavoj 15, Zagreb, Croatia

Full list of author information is available at the end of the article
}

has been shown as inexpensive and safe tool [6, 7], often associated with mortality risks in patients with chronic respiratory diseases $[8,9]$, cystic fibrosis $[10]$ and hypertension [11].

In the past two decades, the 6MWT has been increasingly used in children with chronic diseases [10, 12-15]. Although its practical implications have been well-documented [16], little evidence has been provided for normative data in healthy children [17]. Specifically, a study by Cacau et al. [17] has identified twelve studies establishing the $6 \mathrm{MWT}$ standards. The reference values reviewed in the study were very heterogenous, particularly because of small sample size and different settings [18-23]. Thus, the findings obtained from the aforementioned studies may not be applicable for the population of children in other countries. Thus, both country-specific and worldwide normative values for the $6 \mathrm{MWT}$ should be 
generated, for the purposes of tracking annual changes of functional status within the country and to compare the data between the countries. Since studies have shown a great range in walking distance [17], each country should implement a study to determine normative values for the 6MWT, considering sociodemographic, anthropometric and other cultural differences. The newly established data for the 6MWT would help health-related professionals and physical education teachers for initial screening of functional exercise capacity and detecting those individuals at higher risk of 'poor' performance, from which special interventions and policies aiming to enhance functional performance can be implemented within the school system.

Therefore, the main purpose of the study was to create sex-specific and age-specific normative data for the $6 \mathrm{MWT}$ in a large sample of children.

\section{Methods}

\section{Study participants}

In this observational study, we approached to children between ages 11 and 14 years (50.8\% girls) from randomly selected 10 primary schools located in the city of Zagreb. To be included, children had to be healthy and participated in physical education classes at the time of study and had to be not specifically trained for performance in the administered tests. According to the Croatian Bureau of Statistics for the year 2020 [24], there were 29358 children aged between 11 and 14 years in total. Our sample size was estimated to be 3730 by using $95 \%$ confidence level, $1.5 \%$ margin error and the significance of $p<0.05$. At the beginning, we recruited 4625 children. After the initial screening, 163 were absent and 110 did not attend physical education classes when the tests were being administrated, because of personal issues. Our final sample was comprised of 4352 children (mean age $\pm S D=12 \pm 1$ years, mean height $=156 \pm 10 \mathrm{~cm}$, mean weight $=47 \pm 11 \mathrm{~kg}$, mean body-mass index $=19 \pm 3 \mathrm{~kg} / \mathrm{m}^{2} ; 66 \%$ of girls). Before the testing, physical education teachers responsible for undertaking the tests in each school were briefly instructed about the measurement procedures. The study was approved by the Faculty of Kinesiology, University of Zagreb, Croatia. Parent of each participant and all participants gave informed written consent before enrollment into the study. Analyses and procedures performed in the study were anonymous and conducted in accordance with the Declaration of Helsinki regulations.

\section{MWT}

The 6MWT was used to assess functional capacity of the children. The test was conducted using a 30-m straight corridor with a flat, firm ground and with two cones placed at each end of the course. We followed the testing procedure from the ATS Committee guidelines [16]. Before performing the test, the children were wellrested and instructed to walk around the measured lap. If a child had any kind of problem during the test (respiratory or locomotor issues, fatigue), they were told to slow down or stop the test. Children were divided into small groups of five to perform the test, to prevent from competition [2]. The final score was expressed in distance covered in meters $(\mathrm{m})$ during a 6-min period. In addition, we calculated the mean speed of each child by dividing the final score by 6 [6-min distance covered (m)/6].

Height and weight were objectively measured using portable stadiometer and digital scale with a precision of $0.1 \mathrm{~mm}$ and $0.1 \mathrm{~kg}$. Body-mass index was calculated by using the following formula: weight $(\mathrm{kg}) /$ height $\left(\mathrm{m}^{2}\right)$. Age was self-reported.

\section{Data analysis}

Basic descriptive statistics are presented as mean and standard deviation (SD). The Kolmogorov-Smirnov tests showed that data were normally distributed. Sex and age differences were calculated by using analysis of variance (ANOVA) with post hoc comparison test between the groups. To calculate correlations between all the study variables, we used Pearson coefficient of correlation ( $r$ ). All the assumption, including the level of Leven's test of homogeneity, normal population distribution and data independency were met. Multiple regression analysis was performed, to examine the associations between sex, age, height and weight (the independent variables) with the 6MWT (the dependent variable). Standardized beta coefficient of correlation $(\beta)$ and the coefficient of determination $R^{2}$ were used to present the associations. For each variable, we determined sex- and age-specific percentile values (5th, 15th, 25th, 50th, 75th, 85th and 95th) and used the Lambda (L), Mu (M) and Sigma (S) method, in which the optimal power to obtain normality is summarized by a smooth (L) curve and trends in the mean (M) and coefficient of variation (S) are similarly smoothed. Next, all three curves ( $\mathrm{L}, \mathrm{M}$ and $\mathrm{S}$ ) are summarized based on the power of age-specific Box-Cox power transformations for normalizing the data [25]. The LMS method assumes that the data can be normalized by using a power transformation and removing the skewness. For correlation and multiple regression analyses, we calculated the $95 \%$ confidence interval $(95 \% \mathrm{CI})$ with the significance level of $p<0.05$. All analyses were performed in Statistical Packages for Social Sciences version 24. (SPSS Inc., Chicago, Illinois, USA). 


\section{Results}

Basic descriptive statistics are presented in Table 1. Boys were taller, heavier and had higher body-mass index values, compared to girls. The mean distance walked in $6 \mathrm{~min}$ was $576 \pm 93 \mathrm{~m}$ in boys and $545 \pm 92 \mathrm{~m}$ in girls, respectively. The mean walking speed for boys and girls was $98 \pm 5 \mathrm{~m} / \mathrm{min}$ and $91 \pm 6 \mathrm{~m} / \mathrm{min}$.

The 6MWT was significantly correlated with age $(r=0.24,95 \%$ CI $0.21-0.26, p<0.001)$, height $(r=0.09$, 95\% CI $0.06-0.12, p<0.001)$, weight $(r=-0.13,95 \%$ $\mathrm{CI}-0.16$ to $-0.10, p<0.001)$ and body-mass index $(r=-0.26,95 \% \mathrm{CI}-0.29$ to $-0.23, p<0.001)$. Multiple regression analysis showed that sex (unstandardized $\beta$ coefficient $=-0.81 .7,95 \% \mathrm{CI}-92.8$ to -70.5 , $p<0.001$ ), age (unstandardized $\beta$ coefficient $=62.0$, 95\% CI 56.0-68.1, $p<0.001$ ), height (unstandardized $\beta$ coefficient $=3.0,95 \%$ CI $2.1-3.8, p<0.001)$ and weight (unstandardized $\beta$ coefficient $=-7.5,95 \%$
CI -8.2 to $-6.8, \quad p<0.001)$ entered simultaneously into the model were significantly associated with the $6 \mathrm{MWT}\left(R=0.44, R^{2}=19 \%\right.$, standard error of estimates $=168.5 \mathrm{~m}, p<0.001)$.

Normative values for the $6 \mathrm{MWT}$ are presented in Table 2. A significant rising trend in the 6MWT in both sexes was observed. Significant differences between sex $\left(F_{1,7}=144.05, p<0.001\right)$, age $\left(F_{3,7}=92.68, p<0.001\right)$ and sex*age interaction $\left(F_{3,7}=5.50, p<0.001\right)$ were observed. Specifically, boys achieved better walking distance, compared to girls (mean difference $=69.2 \mathrm{~m}, p<0.001$ ), older boys and girls performed better, compared to their younger counterparts (11-year-olds $=526.7 \mathrm{~m}$; 12 -yearolds $=552.5 \mathrm{~m} ; 13$-year-olds $=573.6 \mathrm{~m}$ and 14-yearolds $=592.3 \mathrm{~m} ; p<0.001$ for all age groups) and boys in one age group performed better, compared to girls in the same age group $(p<0.001)$.

Figure 1 shows sex- and age-specific normative data for distance covered and mean walking speed of the 6MWT.

Table 1 Basic descriptive statistics of the study participants $(N=4352)$

\begin{tabular}{lcccc}
\hline Study variables & $\begin{array}{l}\text { Total }(\boldsymbol{N}=\mathbf{4 3 5 2}) \\
\text { Mean } \pm \text { SD }\end{array}$ & $\begin{array}{l}\text { Boys }(\boldsymbol{N}=\mathbf{1 4 7 1}) \\
\text { Mean } \pm \text { SD }\end{array}$ & \multicolumn{2}{c}{$\begin{array}{l}\text { Girls }(\boldsymbol{N}=\mathbf{2 8 8 1}) \\
\text { Mean } \pm \text { SD }\end{array}$} \\
\hline Age (years) & $12 \pm 1$ & $12 \pm 1$ & $12 \pm 1$ & 0.890 \\
Height $(\mathrm{cm})$ & $156 \pm 10$ & $159 \pm 11$ & $155 \pm 10$ & $<0.001$ \\
Weight $(\mathrm{kg})$ & $47 \pm 11$ & $49 \pm 13$ & $46 \pm 10$ & $<0.001$ \\
Body-mass index $\left(\mathrm{kg} / \mathrm{m}^{2}\right)$ & $19 \pm 3$ & $19 \pm 3$ & $19 \pm 3$ & 0.756 \\
6MWT $(\mathrm{m})$ & $561 \pm 93$ & $576 \pm 93$ & $545 \pm 92$ & $<0.001$ \\
Speed $(\mathrm{m} / \mathrm{min})$ & $94 \pm 5$ & $98 \pm 5$ & $91 \pm 6$ & $<0.001$ \\
\hline
\end{tabular}

$p<0.05$

Table 2 Normative data for the 5th, 15th, 25th, 50th (median), 75th, 85th and 95th percentile of the 6MWT in the study participants $(N=4352)$

\begin{tabular}{|c|c|c|c|c|c|c|c|c|c|c|}
\hline Measure & Sex & Age & $\mathrm{N}$ & P5 & P15 & P25 & P50 & P75 & P85 & P95 \\
\hline \multirow[t]{8}{*}{ 6MWT (m) } & Boys & 11 & 404 & 385 & 464 & 490 & 560 & 605 & 630 & 665 \\
\hline & & 12 & 387 & 388 & 465 & 503 & 570 & 630 & 660 & 700 \\
\hline & & 13 & 385 & 420 & 490 & 527 & 595 & 653 & 675 & 723 \\
\hline & & 14 & 295 & 452 & 525 & 565 & 630 & 680 & 708 & 750 \\
\hline & Girls & 11 & 675 & 349 & 420 & 455 & 512 & 570 & 576 & 630 \\
\hline & & 12 & 767 & 391 & 450 & 495 & 540 & 600 & 630 & 690 \\
\hline & & 13 & 732 & 420 & 462 & 500 & 560 & 615 & 660 & 710 \\
\hline & & 14 & 707 & 435 & 490 & 513 & 570 & 625 & 685 & 743 \\
\hline \multirow[t]{8}{*}{ Speed (m/min) } & Boys & 11 & 404 & 64 & 78 & 82 & 94 & 101 & 105 & 111 \\
\hline & & 12 & 387 & 65 & 78 & 84 & 95 & 105 & 110 & 117 \\
\hline & & 13 & 385 & 70 & 82 & 88 & 99 & 109 & 113 & 121 \\
\hline & & 14 & 295 & 76 & 88 & 94 & 105 & 114 & 118 & 125 \\
\hline & Girls & 11 & 675 & 58 & 70 & 76 & 86 & 95 & 96 & 105 \\
\hline & & 12 & 767 & 65 & 75 & 83 & 90 & 100 & 105 & 115 \\
\hline & & 13 & 732 & 70 & 77 & 84 & 94 & 103 & 110 & 119 \\
\hline & & 14 & 707 & 73 & 82 & 86 & 95 & 104 & 114 & 124 \\
\hline
\end{tabular}




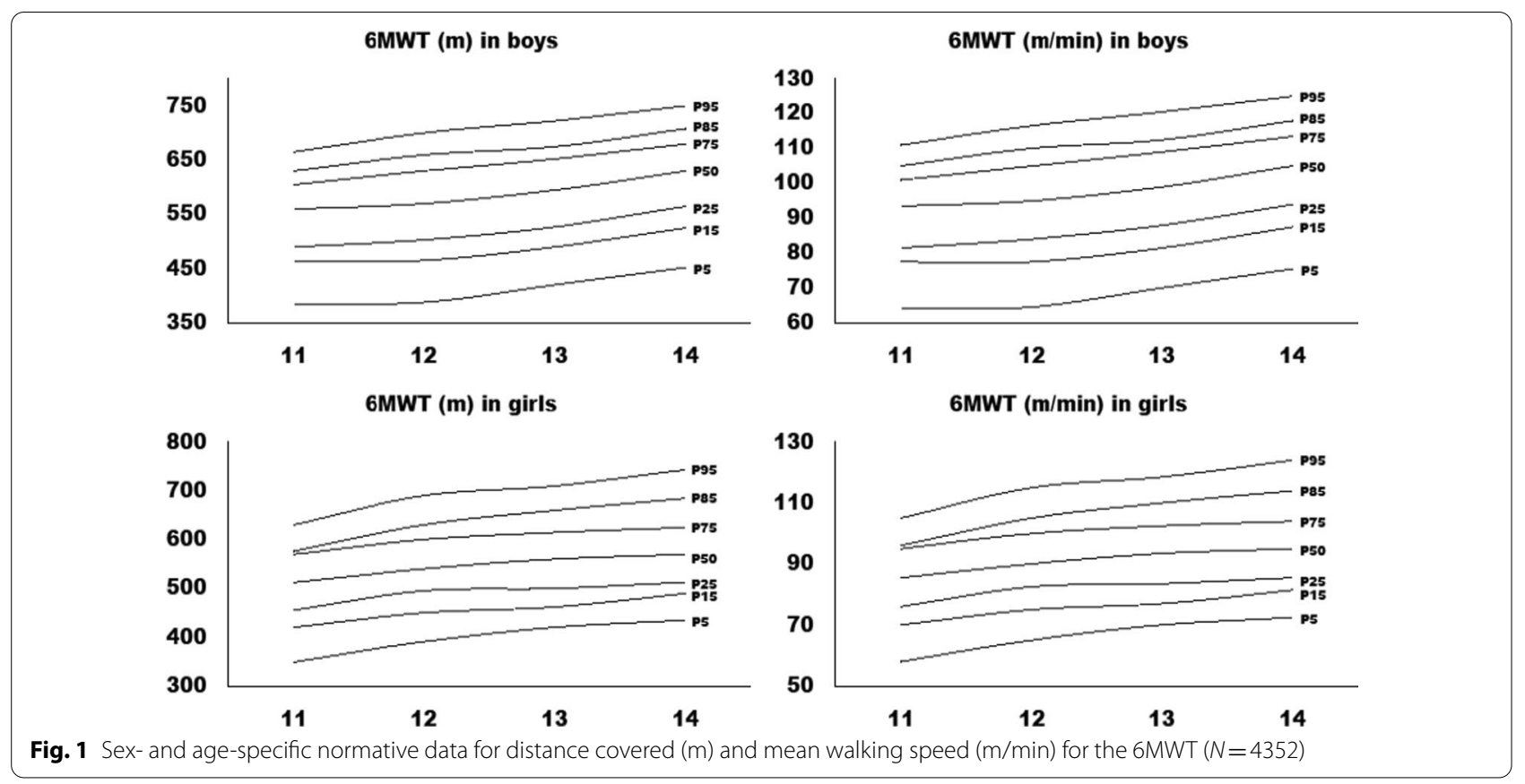

In general, the distance walked gradually increased by age, with the similar rate of change between ages in both sexes $(p<0.001)$. Boys in the specific age group performed better, compared to girls in the same age group.

\section{Discussion}

The main purpose of the study was to create sex-specific and age-specific normative data for the 6MWT in a large sample of children aged between 11 and 14 years. The main findings of the study are: (1) boys performed better in the 6MWT, compared to girls, (2) older children performed better in the 6MWT, compared to their counterparts and (3) in the same age groups, boys outperformed girls in the 6MWT.

This is one of the first population-based studies aiming to establish normative data for the 6MWT in children. Our findings are comparable to previous studies conducted in different settings and with small sample sizes $[2,4,5,17-23]$. Normative data for the 6MWT in healthy children have been reported in the United Kingdom [2], Taiwan [4], Turkey [5], United States [18], Saudi Arabia [19], Tunisia [20], Switzerland [21], Brazil [22], India [23] and Italy [26]. The mean value for distance covered in $6 \mathrm{~min}$ for the aforementioned studies ranged between $470 \pm 59 \mathrm{~m}$ and $707 \pm 102[2,20]$. The findings of this study are mostly similar to normative data from Turkey [5], Saudi Arabia [19] and Brazil [22], while the shortest distance covered is observed in the United Kingdom [2], United States [18] and Tunisia [20]. The great range for the $6 \mathrm{MWT}$ of previous findings may be explained by the following parameters: (1) different age groups (from 4 to 17 years old $[2,21]$ ),

(2) sex distribution (boys and girls $v s$. only boys $v s$. only girls [19]), (3) convenience sample size without the calculation, (4) using different corridor length; i.e. from 15 to $20 \mathrm{~m}[2,18]$, and (5) performing the test once or twice, with a 15,30 or 60 min of interval $[18,20,22]$ Moreover, a few studies have used physiological and biomechanical parameters, like heart rate, blood pressure, oxygen saturation or stride-length, which have all been associated with 6-min distance covered [12, 21]. Indeed, the normative data from previous studies must be taken with caution. First, the systematic review of Cacau et al. [17] has shown a great heterogeneity in distance covered for up to $159 \mathrm{~m}$ between the studies, pointing out that minimally clinically significant difference in children has not yet been established. Of note, such difference has been presented for adult population with cardiovascular and pulmonary diseases [27, 28]. Second, none of the study has used a sample size calculation, which makes difficult to generalize the findings to the whole population of children.

It has been well-documented, that the $6 \mathrm{MWT}$ is a reliable and valid measure to assess pulmonary capacities obtained from a submaximal level $[1,2,17]$ Its practical implication has been highlighted in different populations, especially in those with disorders or postoperative stages [8-15] Although an effort for the $6 \mathrm{MWT}$ normative data in children has been made, this is the first study using a population-based sample and a 
sample size calculation to provide standards in Caucasian children between 11 and 14 years.

This study has a few strengths. We based the findings of the study on a large sample of 11-14-year-olds. The protocol for the 6MWT was followed according to the ATS Committee, to standardize the measuring procedure.

However, this study is not without limitation. First, by using a longitudinal design, we would be able to track biological changes in the 6MWT. Second, we did not collect the data regarding socioeconomic, health-related or biomechanical parameters. Previous studies have used heart rate, blood pressure, oxygen saturation, physical activity and stride-length as significant correlates of the $6 \mathrm{MWT}[12,21]$. Third, the distance covered was measured only once for each child, providing no information about the test-retest reliability for the studied sample. Fourth, the present study was unable to detect the level of motivation or coordination between and within the groups of children performing the 6MWT. Finally, the $6 \mathrm{MWT}$ wasn't performed twice with a 30 -min rest interval, as recommended by the ATS Committee [16]. Therefore, future research should be performed for each country to determine normative data for the 6MWT in the pediatric population, regarding test-retest reliability and validity properties (the associations between the $6 \mathrm{MWT}$ and health-related outcomes). Also, reference equations with sociodemographic, anthropological and health-related indicators for cross-correlation and predictive purposes need to be developed, in order to compare the data between the countries.

\section{Conclusions}

This is the first population-based study providing sexspecific and age-specific normative data for the 6MWT in a large sample of apparently healthy children aged between 11 and 14 years. Our newly proposed normative data should serve in clinical and school-based settings; to screen for functional exercise capacity and to detect those individuals with 'poor' performance in the 6MWT. These individuals should be a 'target group' for special interventions and policies aiming to enhance the performance in the 6MWT.

\section{Abbreviations}

ANOVA: Analysis of variance; L: Lambda; M: Mu; S: Sigma; SD: Standard deviation; 6MWT: Six-minute walk test; 95\% Cl: 95 Percent confident interval.

\section{Acknowledgements}

The authors would like to thank all the physical education teachers, children and their parents or guardians for enthusiastic participation in the study.

\section{Authors' contributions}

VP conducted the study. LŠ analyzed the data. MK, LŠ and VP wrote and drafted the manuscript. The author(s) read and approved the final version of the manuscript.
Funding

The paper was self-funded.

Availability of data and materials

The datasets used and/or analyzed during the current study are available from the corresponding author on reasonable request.

\section{Declarations}

Ethics approval and consent to participate

The study was approved by the Faculty of Kinesiology, University of Zagreb, Croatia. The informed consent voluntarily was signed by the participants, participants' parents or their guardians.

\section{Consent for publication}

The informed consent voluntarily was signed by the participants, participants' parents or their guardians.

\section{Competing interests}

The authors declare that they have no competing interests.

\section{Author details}

${ }^{1}$ Department of General and Applied Kinesiology, Faculty of Kinesiology, University of Zagreb, Horvaćanski zavoj 15, Zagreb, Croatia. ${ }^{2}$ Department of Sport Motorics and Methodology in Kinanthropology, Faculty of Sports Studies,

Masaryk University, Brno, Czech Republic. ${ }^{3}$ Department of Educational Studies, Faculty of Teacher Education, University of Rijeka, Rijeka, Croatia. ${ }^{4}$ Recruitment and Examination (RECETOX), Faculty of Science, Masaryk University, Brno, Czech Republic

Received: 16 March 2021 Accepted: 10 September 2021

Published online: 21 September 2021

\section{References}

1. Casanova C, Celli BR, Barria P, Casas A, Cote C, de Torres JP, et al. The 6-min walk distance in healthy subjects: reference standards from seven countries. Eur Respir J. 2011;37(1):150-6.

2. Lammers AE, Hislop AA, Flynn Y, Haworth SG. The 6-minute walk test: normal values for children of 4-11 years of age. Arch Dis Child. 2008;93(6):464-8.

3. Chetta A, Zanini A, Pisi G, Aiello M, Tzani P, Neri M, et al. Reference values for the 6-min walk test in healthy subjects 20-50 years old. Respir Med. 2006;100(9):1573-8.

4. Chen $\mathrm{CA}$, Chang $\mathrm{CH}$, Lin MT, Hua YC, Fang WQ, Wu MH, et al. Six-minute walking test: normal reference values for Taiwanese children and adolescents. Acta Cardiol Sin. 2015;31(3):193-201.

5. Kanburoglu MK, Ozdemir FM, Ozkan S, Tunaoglu FS. Reference values of the 6-minute walk test in healthy Turkish children and adolescents between 11 and 18 years of age. Respir Care. 2014;59(9):1369-75.

6. Papathanasiou JV, llieva E, Marinov B. Six-minute walk test: an effective and necessary tool in modern cardiac rehabilitation. Hellenic J Cardiol. 2013;54(2):126-30.

7. Enright PL, McBurnie MA, Bittner V, Tracy RP, McNamara R, Arnold A, et al. The 6-min walk test: a quick measure of functional status in elderly adults. Chest. 2003:123(2):387-98.

8. Casanova C, Cote C, de Torres JP, Aguirre-Jaime A, Marin JM, Pinto-Plata V, et al. Inspiratory-to-total lung capacity ratio predicts mortality in patients with chronic obstructive pulmonary disease. Am J Respir Crit Care Med. 2005;171(6):591-7.

9. Pinto-Plata VM, Cote C, Cabral H, Taylor J, Celli BR. The 6-min walk distance: change over time and value as a predictor of survival in severe COPD. Eur Respir J. 2004;23(1):28-33.

10. Gulmans VA, van Veldhoven NH, de Meer K, Helders PJ. The six-minute walking test in children with cystic fibrosis: reliability and validity. Pediatr Pulmonol. 1996;22:85-9.

11. Miyamoto S, Nagaya N, Satoh T, Kyotani S, Sakamaki F, Fujita M, et al. Clinical correlates and prognostic significance of six-minute walk test in patients with primary pulmonary hypertension. Comparison 
with cardiopulmonary exercise testing. Am J Respir Crit Care Med. 2000;161:487-92.

12. Nixon PA, Joswiak ML, Fricker FJ. A six-minute walk test for assessing exercise tolerance in severely ill children. J Pediatr. 1996;129:362-6.

13. Andrade LB, Silva DA, Salgado TL, Figueroa JN, Lucena-Silva N, Britto MC. Comparison of six-minute walk test in children with moderate/ severe asthma with reference values for healthy children. J Pediatr. 2014;90(3):250-7.

14. Bartels B, de Groot JF, Terwee CB. The six-minute walk test in chronic pediatric conditions: a systematic review of measurement properties. Phys Ther. 2013;93(4):529-41.

15. Rhodes J, Tikkanen AU, Jenkins KJ. Exercise testing and training in children with congenital heart disease. Circulation. 2010;122(19):1957-67.

16. ATS Committee on Proficiency Standards for Clinical Pulmonary Function Laboratories. ATS statement: guidelines for the six-minute walk test. Am J Respir Crit Care Med. 2002;166(1):111-7.

17. Cacau LA, de Santana-Filho VJ, Maynard LG, Gomes MN, Fernandes M, Carvalho VO. Reference values for the six-minute walk test in healthy children and adolescents: a systematic review. Braz J Cardiovasc Surg. 2016:31(5):381-8.

18. Keppler SE, Muir N. Reference values on the 6-minute walk test for children living in the United States. Wolters Kluwer Health, Lippincott Williams \& Wilkins and Section on Pediatrics of the American Physical Therapy Association. 2011:34-40.

19. Rahman SAA, Alnegimshi AA. Normative values of six-minute walk distance for healthy Saudi girls. World Appl Sci J. 2014;32(8):1721-30.

20. Saad HB, Prefaut C, Missaoui R, Mohamed IH, Tabka Z, Hayot M. Reference equation for 6-min walk distance in healthy North African children 6-16 years old. Pediatr Pulmonol. 2009;44(4):316-24

21. Ulrich S, Hildenbrand FF, Treder U, Fischler M, Keusch S, Speich R, et al. Reference values for the 6-minute walk test in healthy children and adolescents in Switzerland. BMC Pulm Med. 2013;13:49.
22. Priesnitz CV, Rodrigues GH, Stumpf Cda S, Viapiana G, Cabral CP, Stein RT, et al. Reference values for the 6-min walk test in healthy children aged 6-12 years. Pediatr Pulmonol. 2009;44(12):1174-9.

23. D'Silva C, Vaishali K, Venkatesan P. Six-minute walk test-normal values of school children aged 7-12 y in India: a cross-sectional study. Indian J Pediatr. 2012;79(5):597-601.

24. Croatian Bureau of Statistics. First release of the basic schools; end of 2018/2019 school year and beginning of 2019/2020 school year. https://www.dzs.hr/Hrv_Eng/publication/2020/08-01-02_01_2020.htm. Assessed on March 12, 2021.

25. Cole TJ. The LMS method for constructing normalized growth standards. Eur J Clin Nutr. 1990;44(1):45-60.

26. Vandoni M, Correale L, Puci MV, Galvani C, Codella R, Togni F, et al. Six minute walk distance and reference values in healthy Italian children: A cross-sectional study. PLOS ONE. 2018;13(10):e0205792.

27. Shoemaker MJ, Curtis AB, Vangsnes E, Dickinson MG. Clinically meaningful change estimates for the six-minute walk test and daily activity in individuals with chronic heart failure. Cardiopulm Phys Ther J. 2013;24(3):21-9.

28. Polkey MI, Spruit MA, Edwards LD, Watkins ML, Pinto-Plata V, Vestbo J, et al. Six-minute-walk test in chronic obstructive pulmonary disease: minimal clinically important difference for death or hospitalization. Am J Respir Crit Care Med. 2013;187(4):382-6.

\section{Publisher's Note}

Springer Nature remains neutral with regard to jurisdictional claims in published maps and institutional affiliations.
Ready to submit your research? Choose BMC and benefit from:

- fast, convenient online submission

- thorough peer review by experienced researchers in your field

- rapid publication on acceptance

- support for research data, including large and complex data types

- gold Open Access which fosters wider collaboration and increased citations

- maximum visibility for your research: over $100 \mathrm{M}$ website views per year

At BMC, research is always in progress.

Learn more biomedcentral.com/submissions 